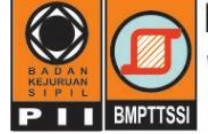

MEDIA KOMUNIKASI TEKNIK SIPIL

Website : mkts.sipil.undip.ac.id

E-ISSN : 2549 - 6778

DOI: https://doi.org/10.14710/mkts.v23i1.14738

\title{
Analisis Efektivitas Model Perkuatan dengan Injeksi Semen untuk Peningkatan Angka Keamanan Lereng
}

\author{
"Sumirin, Rifqi Brilyanto Arief \\ Jurusan Teknik Sipil, Fakultas Teknik, Universitas Islam Sultan Agung, Semarang \\ ${ }^{*}$ sumirinms@gmail.com
}

Received: 19 Mei 2017 Revised: 29 Mei 2017 Accepted: 7 Juni2017

\begin{abstract}
The problem of slope stability can be overcome by grouting of cement paste. But, the question often arises as to the extent of grouting of cement paste can increase the factor of safety. This study aims to determine the effectiveness of the effect of grouting on increasing safety factor on the slope of embankment. Experiments have been conducted in the laboratory using 6 types of mixed samples of sand and coarse aggregate. Field testing was conducted on 1 model to determine the effectiveness of grouting. The results of the experiments show that the injection of cement paste in this study proved to be effective in strengthening the embankment with the content of coarse aggregate $60 \%$. The increase factor of safety (FS) using grouting is from FS=1.9 $(33.3 \%)$ to $F S=2.80$ (90.0\%). Factors determining the effectiveness of injection are: (a) injection method with drilling technique before injection to form cement column; (b) the optimum of water-cement ratio w/c = 1.5; (c) the ratio of spacing and injection diameter $L g / D g=8$, the depth of injection 0.75 from the height of the embankment.
\end{abstract}

Keywords: Slope, embankment, factor of safety, grouting

\begin{abstract}
Abstrak
Masalah kelongsoran pada lereng timbunan tanah dapat diatasi dengan cara injeksi pasta semen. Namun sering timbul pertanyaan sejauh mana injeksi pasta semen dapat meningkatkan angka keamanan. Penelitian ini bertujuan untuk mengetahui efektivitas pengaruh injeksi cairan semen terhadap peningkatan angka keamanan lereng pada timbunan tanah granular. Pengujian telah dilakukan di laboratorium menggunakan 6 jenis sampel campuran pasir dan batu krosok. Pengujian di lapangan dilakukan terhadap 1 model lereng timbunan untuk mengetahui efektivitas pelaksanaan injeksi pasta semen. Hasil-hasil percobaan menunjukkan injeksi pasta semen dalam penelitian ini terbukti efektif untuk memperkuat lereng tanah bergradasi kasar dengan kandungan batu krosok sampai 60\%. Peningkatan angka keamanan dengan perkuatan injeksi pasta semen mulai dari $F S=1,9(33,3 \%)$ sampai $F S=2,80$ (90,0\%). Faktor yang menentukan efektivitas injeksi adalah : (a)metode injeksi dengan teknik pengeboran sebelum diinjeksi sehingga terbentuk kolom semen; (b)faktor air semen yang optimum $w / c=1,5 ;$ (c) rasio jarak dan diameter injeksi $\mathrm{Lg} / \mathrm{Dg}=8$, kedalaman injeksi 0,75 dari ketinggian timbunan.
\end{abstract}

Kata-kata kunci: Lereng, timbunan, angka keamanan, injeksi

\section{Pendahuluan}

Pekerjaan timbunan tanah pada umumnya digunakan untuk konstruksi jalan raya atau pekerjaan sipil lainnya. Dalam pelaksanaan pekerjaan timbunan banyak dijumpai kemiringan lereng cukup terjal tanpa perkuatan dinding penahan tanah atau perlindungan lereng yang mengakibatkan terjadi kasus kelongsoran. Salah satu contoh yang dijumpai di Indonesia adalah pada tahun 2006 terjadi kelongsoran lereng di jalan tol Cipularang yang mengakibatkan badan jalan ambles (Liong, 2006). Solusi yang dilakukan untuk mengatasi kelongsoran antara lain adalah dengan melakukan injeksi (grouting) cairan semen pada timbunan tanah dengan arah memotong bidang gelincir. Seberapa besar faktor atau angka keamanan kestabilan lereng timbunan tanah dengan perkuatan injeksi cairan semen adalah merupakan hal yang penting untuk diketahui. 
Seperti yang disarankan oleh Abramson et al., (1995) bahwa ada lima metode stabilisasi lereng timbunan yaitu: pengurangan beban, drainase, buttressing, perkuatan (reinforcement) dan dinding penahan tanah. Salah satu metode perkuatan lereng adalah grouting. Grouting atau injeksi adalah metode penyuntikan bahan semi kental (slurry material) ke dalam tanah atau batuan melalui lubang bor, dengan tujuan menutup diskontruksi terbuka, rongga-rongga dan lubang-lubang pada lapisan yang dituju untuk meningkatkan kekuatan tanah (Dwiyanto, 2005; Salimian et al., 2017; Zhang, 2017; Zhang et al., 2017; Cai et al., 2017; Alberti et al., 2017). Berdasarkan fungsinya grouting terbagi menjadi dua macam yaitu grouting tirai dan grouting konsolidadi (Udiana, 2013). Desain Campuran Semen dan Air pada Pekerjaan Grouting Proyek Bendungan/Waduk Nipah Madura-Jawa Timur Bahan-bahan yang biasanya dijadikan sebagai material pengisi pada grouting diantaranya campuran semen dan air; campuran semen, abu batu dan air; campuran semen, clay dan air; campuran semen, clay, pasir dan air; asphalt; campuran clay dan air dan campuran bahan kimia (Suryo Hapsoro \& Tri Utomo, 2007).

Suharjanto dan Teguh Widodo (2008) melakukan grouting semen dan perkuatan geotekstil sebagai solusi perbaikan tanah dasar ruas jalan SmewahSukaraja yang merupakan jalan masuk menuju lokasi pemboran minyak Sukaraja. Hasilnya menunjukkan bahwa tanah dasar ruas jalan Smewah-Sukaraja memiliki nilai batas cair $35,53 \%$, indeks plastisitas 15,98, CBR 0,1" 3,31\% dan CBR 0,2" 2,65\% sehingga tidak memenuhi persyaratan sebagai subgrade jalan. Waktu pelaksanaan perbaikan tanah metode semen dan perkuatan geotekstil adalah 120 hari, dan 90 hari. Anggaran biaya perbaikan tanah metode semen-tanah dan perkuatan geotekstil masingmasing adalah Rp5.279.500.000,00 dan Rp5.223.000.000,00.

Untuk mengetahui perilaku kelongsoran lereng pada timbunan, beberapa peneliti terdahulu telah melakukan kajian terhadap model. Teaching model pada Experimental Soil Mechanics and Dynamics Laboratory Nanyang Technological University memakai bejana transparan (kaca) dan pasir untuk memodelkan tekanan pasif tanah ketika didesak oleh deformasi lateral dinding. Allersma (2006) mempublikasikan pemodelan perbaikan stabilitas lereng tanggul dengan pada bejana kaca untuk memodelkan perbaikan angka keamanan dan deformasinya, dengan metode geotextile dan soil nailing. Peneliti dari Indonesia, Fabian dan Manoppo (2011), juga melakukan pemodelan lereng timbunan di laboratorium dengan menggunakan bejana kaca.

Angka atau faktor keamanan (factor of safety = FS) timbunan tanah didefinisikan sebagai perbandingan antara jumlah kekuatan atau gaya geser sepanjang bidang longsor atau gelincir $(\tau)$ dengan gaya dorong $(\mathrm{S})$,

$\mathrm{FS}=\tau / \mathrm{S}$

dimana kekuatan geser dihitung dari $\tau=\mathrm{W} \cos (\alpha)$ $\tan (\phi)+c$ L, sedangkan gaya dorong dihitung dengan $\mathrm{S}=(\mathrm{W}+\mathrm{V}) \sin (\alpha), \mathrm{W}=$ berat segmen tanah, $\mathrm{V}=$ beban luar, $\mathrm{c}=$ kohesi tanah, $\mathrm{L}=$ jumlah panjang bidang gelincir, $\alpha=$ sudut kemiringan lereng, dan $\phi=$ sudut geser dalam tanah (Abramson et al., 1995), Gambar 1. Makin besar angka kemanan FS maka timbunan tanah makin kecil kemungkinan terjadinya kelongsoran.

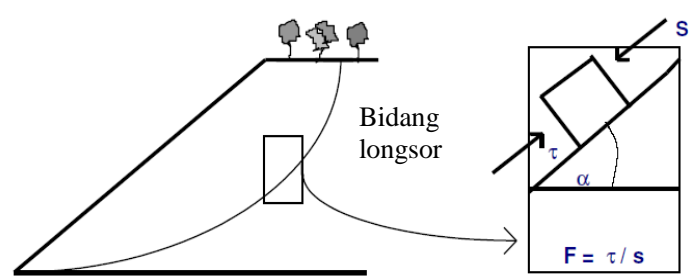

Gambar 1. Bidang longsor timbunan tanah

Tujuan penelitian ini adalah untuk mengetahui efektivitas pengaruh injeksi cairan semen terhadap peningkatan angka keamanan lereng pada timbunan tanah granular. Percobaan dilakukan dengan variasi faktor air semen w/c, variasi gradasi butiran tanah dan variasi kemiringan lereng akan menghasilkan variasi angka keamanan lereng.

\section{Metode Penelitian}

\section{Pengujian properties material}

Pengujian telah dilakukan menggunakan peralatan dan fasilitas yang ada di Laboratorium Mekanika Tanah dan Laboratorium Struktur dan Bahan Fakultas Teknik Universitas Islam Sultan Agung Semarang pada tahun 2015-2016. Data material dan benda uji yang digunakan disajikan pada Tabel 1. Material grouting yang dipergunakan adalah campuran semen dan air dengan perbandingan semen-air (water cement ratio) : 0,$6 ; 0,8 ; 1 ; 1,2 ; 1,5 ; 1.7 ; 2.0$. Dari percobaan pasta semen yang dibuat, diperoleh faktor $\mathrm{w} / \mathrm{c}=1,5$ dengan jumlah semen yang lebih sedikit tetapi dapat membentuk pasta yang dapat mengeras dan solid. 
Tabel 1. Sampel benda uji

\begin{tabular}{|c|c|c|c|}
\hline $\begin{array}{c}\text { Nomor } \\
\text { benda } \\
\text { uji }\end{array}$ & $\begin{array}{l}\text { Komposisi } \\
\text { benda uji }\end{array}$ & $\begin{array}{l}\text { Kohesi } \\
\text { c (kPa) }\end{array}$ & $\begin{array}{l}\text { Sudut geser } \\
\text { dalam } \emptyset\left({ }^{\circ}\right)\end{array}$ \\
\hline 1 & Pasir $100 \%$ & 0,35 & 26 \\
\hline 2 & $\begin{array}{l}\text { Pasir } 80 \%+ \\
\text { krosok } 20 \%\end{array}$ & 0,57 & 30 \\
\hline 3 & $\begin{array}{l}\text { Pasir } 60 \%+ \\
\text { krosok } 40 \%\end{array}$ & 0,70 & 34 \\
\hline 4 & $\begin{array}{l}\text { Pasir } 40 \%+ \\
\text { krosok } 60 \%\end{array}$ & 1,00 & 38 \\
\hline 5 & $\begin{array}{l}\text { Pasir } 20 \%+ \\
\text { krosok } 80 \%\end{array}$ & 2,50 & 42 \\
\hline 6 & Pasir $100 \%$ & 4,00 & 45 \\
\hline
\end{tabular}

\section{Analisis model}

Pengujian model pada tahap pertama dilakukan dengan analisis menggunakan Program Plaxis(7.2), dengan data properties tanah hasil uji laboratorium. Pada analisis model, sudut lereng dengan kondisi mula-mula $45^{\circ}$ dan ditingkatkan secara bertahap menuju sudut lereng $90^{\circ}$, dimana angka keamanan setiap tahap dicatat (Gambar 2). Sudut lereng yang dicari dalam analisis ini adalah untuk angka keamanan $\mathrm{FS}=1$ yaitu pada kondisi kritis sebelum longsor.

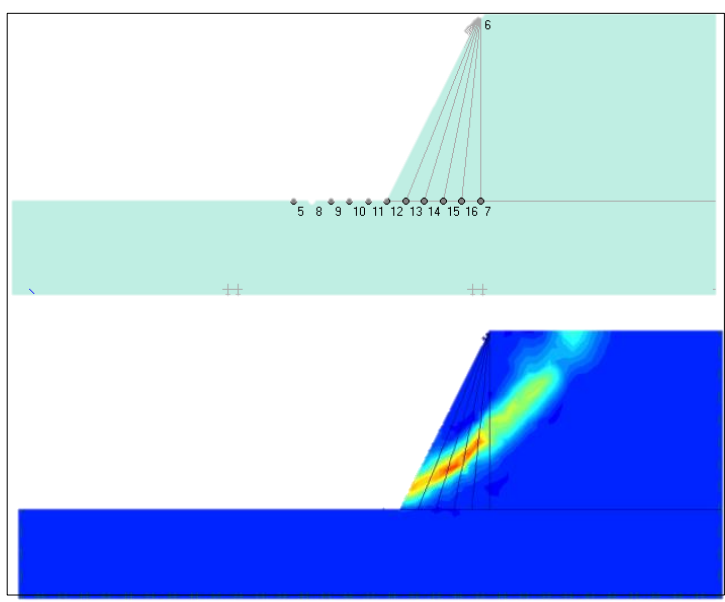

Gambar 2. Analisis model dengan teknik pemotongan untuk mendapatkan sudut lereng $\mathrm{FS}=1$.

\section{Pengujian kelongsoran di laboratorium}

Peralatan dalam penelitian ini menggunakan bejana kaca kedap air yang diisi dengan benda uji bahan tanah pasir dalam penelitian ini pada Gambar 3.

Setiap benda uji (1 sampai dengan 6) sudut lereng tanah dalam bejana kaca dibentuk dengan besaran sudut 45 derajat, kemudian menerjalkan kemiringan lereng secara bertahap menjadi 48, 51 ,
$55,59,63,68,73,79,84$ derajat dan menjenuhkan lereng, sampai didapatkan kelongsoran lereng, seperti dalam Gambar 4. Setiap benda uji mulai dari 1 sampai dengan 6 dan pada sudut berapa terjadi kelongsoran dicatat. Percobaan ini diulang lagi dengan cara yang sama namun dengan benda uji yang sudah digrouting.

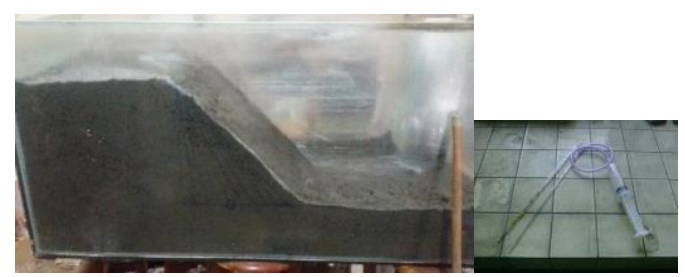

(a)

(b)

Gambar 3. Bejana kaca yang diisi benda uji tanah pasir untuk uji model di laboratorium (a) dan alat untuk injeksi (grouting) cairan semen

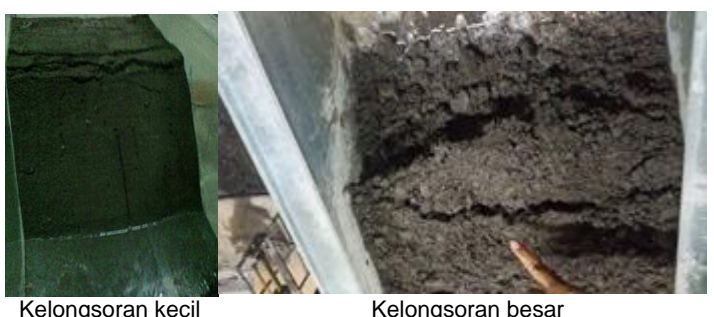

Gambar 4. Model kelongsoran dengan keretakan dan deformasi kecil dan kelongsoran besar yang dijumpai pada pengujian di laboratorium

\section{Pengujian Kelongsoran di Lapangan}

Untuk mengetahui angka keamanan lereng timbunan dengan keadaan yang sesuai dengan lapangan, telah dilakukan pengujian sebuah model lereng dari bahan benda uji 3 (pasir 60\% dan batu krosok 40\%), dengan ukuran dan bentuk model seperti pada Gambar 5. Pemodelan beban digunakan air dari wadah plastik yang flexibel. Tinggi beban air maksimum $1.50 \mathrm{~m}$ diberikan secara bertahap.

Tahap pengujian dilakukan sebagai berikut: (a)Timbunan dibentuk dengan sudut lereng secara bertahap mulai

$45^{\circ}$ hingga curam menuju $90^{\circ}$. Sudut lereng kondisi kritis FS $=1$ diperoleh pada sudut $\alpha=70^{\circ}$. (b)Timbunan tanah diperkuat dengan injeksi pasta semen dengan faktor air semen $\mathrm{w} / \mathrm{c}=1.5$, jarak antar titik $\mathrm{Lg}=50 \mathrm{~cm}$, diameter lubang $\mathrm{Dg}=2.5$ " $=6.25 \mathrm{~cm}$. Agar injeksi efektif dilakukan dengan teknik pengeboran lubang terlebih dahulu sampai mencapai panjang minimal 0,75 tinggi lereng, lalu dimasukkan pasta semen pada Gambar 6. (c) Setelah 7 hari, timbunan tanah yang sudah dinjeksi diberikan beban tumpukan air di atas timbunan 
(Gambar 7) dengan kenaikan secara bertahap sampai mulai terjadi kelongsoran.

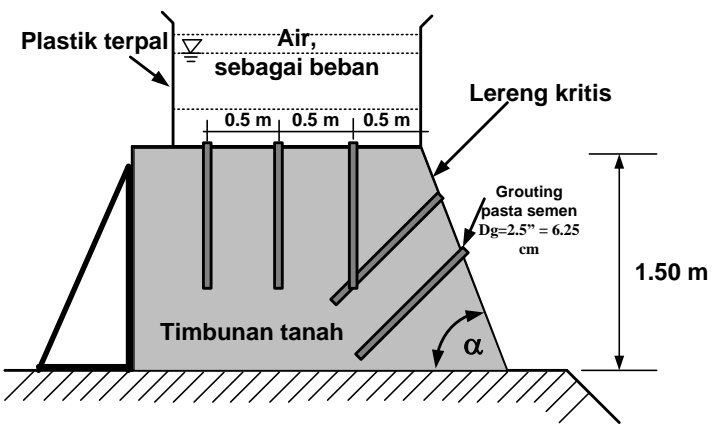

Gambar 5. Model benda uji lereng timbunan tanah untuk pengujian di lapangan.

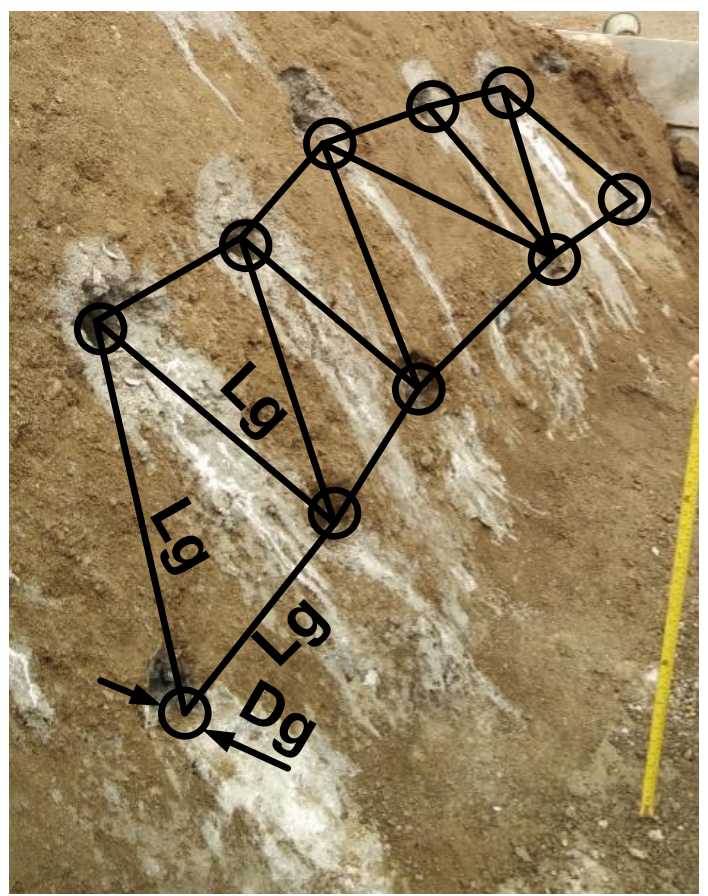

Gambar 6. Pola jarak dan diameter injeksi pasta semen pada bidang lereng.

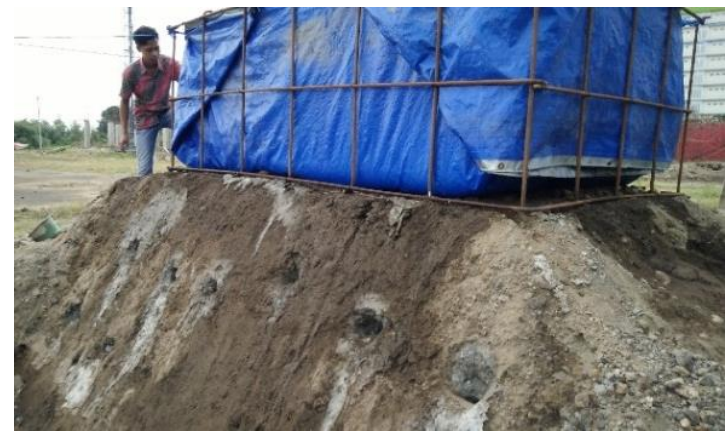

Gambar 7. Pembebanan dengan tumpukan air di atas timbunan tanah yang telah dilakukan injeksi.

\section{Hasil dan Pembahasan}

Hasil-hasil pengujian model benda uji di laboratorium disajikan pada Gambar 8, Gambar 9 dan Tabel 3. Pada Gambar 8 ditunjukkan hubungan antara jenis benda uji pada timbunan terhadap angka keamanan lereng sebelum dilakukan injeksi. Makin meningkat prosentasi material berbutir kasar, maka makin meningkat angka keamanan. Peningkatan ini juga terjadi setelah dilakukan injeksi pasta semen seperti disajikan pada Gambar 9.

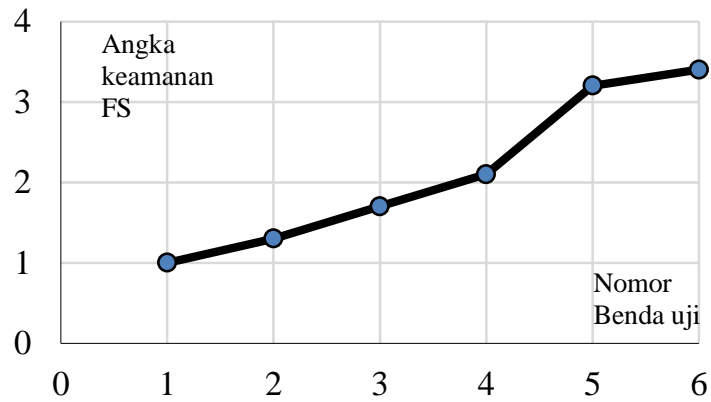

Gambar 8. Pengaruh gradasi tanah terhadap angka keamanan sebelum injeksi pasta semen

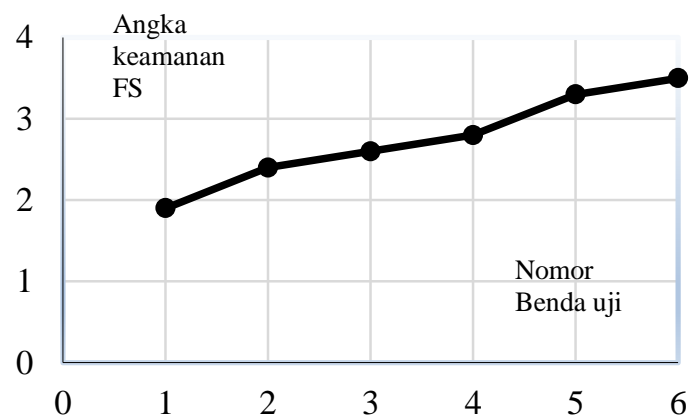

Gambar 9. Pengaruh gradasi tanah terhadap angka keamanan setelah injeksi pasta semen.

Untuk melihat sejauh mana pengaruh injeksi semen terhadap peningkatan angka keamanan, hasil-hasil disajikan pada Tabel 2. Dari tabel ini terlihat bahwa pada benda uji nomor 1,2,3 dan 4, injeksi pasta semen meningkatkan angka keamanan mulai $1,9 \quad(33,3 \%)$ sampai 2,80 $(90,0 \%)$. Hal ini sesuai dengan yang dilakukan oleh Dwiyanto (2005), Salimian et al (2017), Zhang et al (2017), Zhang et al (2017) bahwa injeksi pasta semen sangat efektif untuk meningkatkan angka keamanan terhadap longsor pada lereng tanah pasir yang dicampur dengan batu krosok dengan prosentase mulai 0\% sampai dengan $60 \%$. Pada percobaan di lapangan dengan model lereng timbunan dari bahan benda uji 3 
(pasir 60\% dan batu krosok 40\%), diperoleh kemiringan kritis lereng adalah 70 derajat.

Pada percobaan di lapangan pola grouting diukur dengan diameter dan jarak yang masih mudah dapat dikerjakan. Sedangkan kedalaman ditentukan berdasarkan prinsip kolom semen yang terbentuk memotong tegak lurus bidang gelincir longsoran. Dengan mempertimbangkan efektivitas grouting dan kemudahan pelaksanaan grouting dalam penelitian ini diperoleh diameter kolom semen grouting Dg $=2.5 "=6.25 \mathrm{~cm}$; sedangkan jarak kolom semen grouting adalah $\mathrm{Lg}=50 \mathrm{~cm}$; atau rasio $\mathrm{Lg} / \mathrm{Dg}=8$ pada Gambar 6, sedangkan kedalaman grouting dilakukan dengan rasio kedalaman grouting dan tinggi lereng, $\mathrm{p}=0.75 \mathrm{H}$.

Tabel 2. Hubungan antara jenis material, injeksi semen dan angka keamanan FS lereng.

\begin{tabular}{|c|c|c|c|c|}
\hline $\begin{array}{c}\text { No. } \\
\text { benda } \\
\text { uji }\end{array}$ & $\begin{array}{l}\text { Komposisi } \\
\text { benda uji }\end{array}$ & $\begin{array}{c}\text { Tanpa } \\
\text { injeksi } \\
\text { FS(a) }\end{array}$ & $\begin{array}{c}\text { Dengan } \\
\text { injeksi } \\
\text { FS(b) }\end{array}$ & $\begin{array}{c}\text { Kena- } \\
\text { ikan } \\
\text { FS }\end{array}$ \\
\hline 1 & Pasir $100 \%$ & 1,00 & 1,90 & 90,0 \\
\hline 2 & $\begin{array}{l}\text { Pasir } 80 \%+ \\
\text { krosok 20\% }\end{array}$ & 1,30 & 2,38 & 83,1 \\
\hline 3 & $\begin{array}{l}\text { Pasir } 60 \%+ \\
\text { krosok } 40 \%\end{array}$ & 1,70 & 2,60 & 52,9 \\
\hline 4 & $\begin{array}{l}\text { Pasir } 40 \%+ \\
\text { krosok 60\% }\end{array}$ & 2,10 & 2,80 & 33,3 \\
\hline 5 & $\begin{array}{l}\text { Pasir } 20 \%+ \\
\text { krosok } 80 \%\end{array}$ & 3,20 & 3,40 & 9,7 \\
\hline 6 & Pasir $100 \%$ & 3,40 & 3,66 & 7,6 \\
\hline
\end{tabular}

Hasil pembebanan terhadap lereng timbunan yang telah diinjeksi diperoleh angka keamanan lereng lebih dari 3,1 (FS > 3,1). Kelongsoran yang terjadi bersifat lokal, sehingga untuk terjadi kelongsoran yang besar, atau global angka kemanannya lebih dari 3,1 .

\section{Kesimpulan}

Injeksi (grouting) pasta semen yang dilakukan dalam penelitian ini terbukti efektif untuk memperkuat lereng tanah bergradasi kasar dengan kandungan batu krosok sampai $60 \%$. Peningkatan angka keamanan yang diperoleh dengan perkuatan injeksi pasta semen mulai dari FS = 1,9 (33,3\%) sampai FS $=2,80 \quad(90,0 \%)$. Faktor yang menentukan efektivitas injeksi pasta semen pada timbunan lereng berbutir kasar dalam penelitian ini adalah: (a) metode injeksi yang digunakan adalah dengan teknik pengeboran sebelum diinjeksi pasta semen dan terbukti dengan terbentuknya kolom semen pada lubang bor; (b) faktor air semen yang optimum w/c=1,5; (c) jarak injeksi (Lg) dan diameter injeksi (Dg) yang dapat membentuk kolom dengan rasio $\mathrm{Lg} / \mathrm{Dg}=8$, dengan kedalaman injeksi $\mathrm{p}=0,75 \mathrm{H}$, dimana $\mathrm{H}$ adalah ketinggian timbunan.

\section{Daftar Pustaka}

Abramson, L. W., Lee, T. S., Sharma, S., \& Boyce, G. M. (1995). Slope Stability and Slope Stabilization Methods, John Wiley \& Sons Inc, 441- 582.

Alberti, L., Angelotti, A., Antelmi, M., \& La Licata, I. (2017). A Numerical Study on the Impact of Grouting Material on Borehole Heat Exchangers Performance in Aquifers. Energies, 10(5), 703.

Allersma, H. G. B. (2006). Experimental Research in Geotechnics. Publication Blog, Armsterdam.

Cai, J., Pei, J., Luo, Q., Zhang, J., Li, R., \& Chen, X. (2017). Comprehensive Service Properties Evaluation of Composite Grouting Materials with High-Performance Cement Paste for Semi-Flexible Pavement. Construction and Building Materials, 153, 544-556.

Dwiyanto, J. S. (2005). Hand Out Geoteknik, Departemen Pekerjaan Umum, Bandung.

Fabian, J., \& Manoppo. (2011). Penelitian Potensi Lereng Longsor di Sulut. Publikasi LSM Pendidikan Silo (NGO) \& LSM Pemberdayaan Teknologi dan Perkotaan, Manado.

Liong, G. T. (2006). Proceeding of the Latest Development of Advantage Cement in Geotechnical Engineering, Jakarta.

Salimian, M. H., Baghbanan, A., Hashemolhosseini, H., Dehghanipoodeh, M., \& Norouzi, S. (2017). Effect of Grouting on Shear Behavior of Rock Joint. International Journal of Rock Mechanics and Mining Sciences, 98, 159166.

Suryo H., \& Tri, U. (2007). Stabilisasi Tanah Masa Lalu Masa Kini dan Masa Depan, Naskah Pidato Pengukuhan Guru Besar, Fakultas Teknik Universitas Gajah Mada, Yogyakarta.

Suharjanto \& Teguh, W. (2008). Aspek Teknis dan Ekonomis Metode Injeksi Semen dan Perkuatan Geotekstil Sebagai Solusi Perbaikan Subgrade Ruas Jalan Smewah Ruas Jalan Smewah-Sukaraja. Media Komunikasi Teknik Sipil, 16(3), 243-254.

Udiana, I. M. (2013). Desain Campuran Semen dan Air pada pekerjaan Grouting Proyek Bendungan/Waduk Nipah Madura-Madura Jawa Timur. , Jurnal Teknik Sipil, 2(2), 93-104. 
Zhang, J., Weng, X., Yang, B., Li, Y., Liu, J., \& Jiang, L. (2017). Bonding Characteristics of Grouting Layer in Prefabricated Cement Concrete Pavement. Construction and Building Materials, 145, 528-537.
Zhang, D. M., Huang, Z. K., Yin, Z. Y., Ran, L. Z., \& Huang, H. W. (2017). Predicting the Grouting Effect on Leakage-Induced Tunnels and Ground Response in Saturated Soils. Tunnelling and Underground Space Technology, 65, 76-90. 